\title{
Encuadres noticiosos sobre primeras damas: las expertas, las novatas y las actuales
}

\author{
Framing first ladies: the experts, the novices, \\ and the incumbents
}

\author{
Edrei Álvarez-Monsiváis
}

Cómo citar este artículo:

Álvarez-Monsiváis, Edrei (2020). “Encuadres noticiosos sobre primeras damas: las expertas, las novatas y las actuales". Profesional de la información, v. 29, n. 6, e290621.

https://doi.org/10.3145/epi.2020.nov.21

Artículo recibido el 10-05-2020

Aceptación definitiva: 29-08-2020

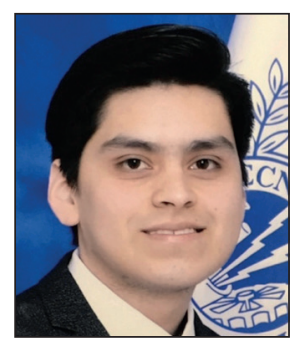

\author{
Edrei Álvarez-Monsiváis \\ https://orcid.org/0000-0003-2779-2012 \\ Universidad Autónoma de Nuevo León \\ Facultad de Ciencias de la Comunicación \\ Paseo del Acueducto cruz con Eucalipto \\ Colonia Del Paseo Residencial \\ 64920 Monterrey (Nuevo León), México \\ edrei.alvarez@gmail.com
}

\section{Resumen}

La figura protocolaria de la primera dama ha sido mediáticamente expuesta a escrutinio ya sea por dirigir un organismo, acompañar a su esposo en eventos o porque se ve incolucrada en conflictos de interés. La bibliografía señala que su papel genera una narrativa de cómo debe ser una mujer ejemplar en su país de origen. En dicho contexto, el presente trabajo tiene como objetivo detectar, a partir del modelo de Winfield (1997), cuáles son los encuadres noticiosos desde los que se cubre a las primeras damas de tres países: Argentina, Estados Unidos y México. Para ello, se seleccionarion tres grupos de primeras damas: uno denominado como las políticas expertas en las que se incluyen las que tenían una carrera política anterior a su cargo y que después buscaron la presidencia de su país (Cristina Fernández, Hillary Clinton y Margarita Zavala); el segundo grupo fue el de las novatas, las cuales llegaron al puesto sin una trayectoria previa (Juliana Awada, Laura Bush y Angélica Rivera); y un tercer grupo conformado por las que actualmente ocupan dicho cargo (Fabiola Yáñez, Melania Trump y Beatriz Gutiérrez Müller). Los diarios analizados fueron La nación, Página/12, The Wall Street Journal, The New York Times, Reforma y La jornada. Por medio del análisis de contenido y del modelo del framing se encontró que el encuadre más utilizado fue el de funcionaria política, lo cual se pronuncia en mayor medida en las políticas expertas y en los diarios opositores al gobierno de su marido. Además, dicho frame les permite a las cónyuges presidenciales expresarse desde citas directas. Se concluye que las primeras damas son abordadas desde marcos noticiosos preferentemente políticos lo cual las dota de un poder blando que le permite intervenir en elecciones, vuelve relevante su opinión y les forma trayectoria política.

\section{Palabras clave}

Encuadres noticiosos; Framing; Primeras damas; Comunicación política; Modelo del encuadre noticioso; Estudios de género; Cónyuges presidenciales; Análisis de contenido; Sexo de periodistas; Orientación política; Periodismo; Poder blando.

\begin{abstract}
The protocol figure of the first lady is subject to media exposure, whether for directing an organization, when accompanying her husband at events, or because she is involved in conflicts of interest. Literature indicates that her role generates a narrative of how an exemplary woman should be in her country. In this context, this paper aims to identify, using the model of Winfield (1997), the news frames used to cover the first ladies of three countries, namely Argentina, USA, and Mexico. For this, three groups of first ladies were selected: a first group of expert politicians, including those who had a political career prior to their position and later sought the presidency of their country (Cristina Fernández, Hillary Clin-
\end{abstract}


ton, and Margarita Zavala); a second group of novices who took the position without a previous career (Juliana Awada, Laura Bush, and Angélica Rivera); and a third group made up of those who currently hold the position (Fabiola Yáñez, Melania Trump, and Beatriz Gutiérrez Müller). The newspapers analyzed were La nación, Página/12, The Wall Street Journal, The New York Times, Reforma, and La jornada. Content analysis and the framing model revealed that the most widely used frame was that of a political official, being more pronounced for expert politicians and in newspapers opposed to her husband's government. Moreover, this allows presidential wives to express themselves via direct quotes. It can thus be concluded that the first ladies are preferably covered from political news frames, which endows them with soft power that allows them to intervene in elections, makes their opinion relevant, and shapes their political career.

\section{Keywords}

News frames: First ladies; Political communication; Framing; Gender studies; Presidential wives; Content analysis; Gender of journalists; Political orientation; Journalism; Soft power.

\section{Introducción}

El cargo de primera dama es un puesto protocolar con una dimensión performativa ya que no tiene funciones institucionalizadas, sino que la mujer en el cargo describe, a partir de las repeticiones de sus acciones, cómo será su rol (Rojas-Zuluaga, 2018). En ese sentido, si bien ellas no presentan un poder directo otorgado por ley, sí tienen el potencial de acceder al poder a partir de significados alternativos (Wideman, 2017).

Existe una tendencia en los mensajes informativos hacia observar a primeras damas que abrazan a ciudadanos, promueven los valores de la familia, acompañan a su esposo en eventos de gobierno y se encargan de labores caritativas (Matějčková, 2019; Paul; Perreault, 2018). Es por medio de estas actividades donde demuestran su feminidad (Goffman, 1979), lo que las vuelve atractivas y empáticas para los medios de comunicación y la ciudadanía en general (Zhang, 2017; Li; Yin, 2018).

En ese sentido, los países latinoamericanos han buscado institucionalizar las actividades de estas figuras a través de proyectos relacionados con mujeres, juventud, infancia y familia (Guerrero-Valencia, 2015). Sin embargo, Rojas-Zuluaga (2018) argumenta que lo que se ha logrado hasta la fecha no es institucionalizar el cargo sino atribuirles roles de género dentro de un entramado institucional, lo cual es reforzado por los medios que comunican las acciones de las primeras damas esencialmente desde su papel tradicional femenino (Colton, 2016). Lo anterior lleva a las cónyuges presidenciales a representarse en términos de las expectativas que la sociedad tiene sobre cómo debe ser la mujer ideal en su país de origen (Kitsch, 2020).

Considerado lo anterior, el presente trabajo tiene la intención de explicar cuáles son los marcos noticiosos desde los que se presentó a nueve cónyuges presidenciales en la prensa de Argentina, México y Estados Unidos. La investigación correlaciona estos resultados con la experiencia política previa de la primera dama, la cantidad de citas directas en el mensaje, el sexo del reportero que escribe la nota y la orientación política del diario que la publica.

\section{Marco teórico}

\subsection{Encuadres noticiosos en la cobertura de primeras damas}

El modelo del framing, de acuerdo con Ardévol-Abreu (2015), consiste en un análisis de los mensajes informativos con el fin de evidenciar los aspectos de una realidad que son remarcadas con mayor frecuencia y que proporcionan un marco de interpretación para las audiencias que se expongan al mensaje.

A estos aspectos se les denomina frames, los cuales

"constituyen una idea profunda y subyacente que provee un contexto dentro del cual los eventos son presentados" (Aruguete, 2017, p. 42).

Los encuadres noticiosos se encuentran de manera latente a partir de frases e ideas clave dentro del texto y son medidos de acuerdo con su ausencia o presencia, esto es, los marcos que son reiterados en detrimento de otros que son excluidos o marginados (Valera-Ordaz, 2016).

Para el caso de las primeras damas, Winfield (1997) definió cinco encuadres o frames desde los cuales es posible estudiar su cobertura mediática. Los clasificó en características tradicionales y no tradicionales. En las primeras, la esposa del presidente puede ser abordada como acompañante presidencial, lideresa de protocolos sociales y labores caritativas. Mientras que en las no tradicionales ubica las situaciones en la que participa de manera ejecutiva, ya sea como elaboradora de leyes o asesora política.

Con base en la taxonomía de la autora y en la adaptación de Álvarez-Monsiváis (2019), a continuación se presentan trabajos que han abordado cada uno de los encuadres de manera teórica y empírica. La idea de este apartado es obtener 
la mayor cantidad de atributos para así crear un conjunto de items desde los que se pueda estudiar cada encuadre. De esta forma, la aproximación utilizada para el modelo del framing es deductiva (Igartua; Humanes, 2004; Igartua; Muñiz; Cheng, 2005). Además, esta investigación parte de la formulación de encuadres específicos (De-Vreese, 2005) en tanto son pertinentes únicamente para la cobertura de primeras damas.

\section{a) Escolta presidencial}

Este encuadre se centra en la cobertura mediática hacia la actividad que la cónyuge presidencial realiza con su esposo, la cual suele ser por mero acompañamiento y apoyo moral (Kellerman, 1978; Winfield; Friedman, 2003). Mediante estas acciones, la primera dama es mostrada de manera pública como el modelo ideal de una esposa y madre que vela por la protección e intereses de su familia, tal como un escolta lo haría (Watson, 1997; Wekkin, 2000; Borrelli, 2002). En ese sentido, la mediatización no es desde ella misma, sino desde su relación con el mandatario o sus hijos.

Erickson y Thomson (2012) explican que las cónyuges presidenciales apoyan a su esposo a través de mostrar el lado humano de éste. Lo anterior ocurre porque un mandatario utiliza sus sustitutos o surrogates, como pueden ser sus hijos o su esposa, con el fin de incrementar su credibilidad (VanHorn, 2010). Recientemente se ha documentado cómo las primeras damas comparten fotografías en sus redes sociales donde presentan la faceta de esposo del mandatario, como se puede observar en la cuenta de Twitter de Michelle Obama (Paul; Perreault, 2018) y en las páginas de Facebook de las esposas de los candidatos presidenciales de República Checa en 2018 (Gejdošová, 2019). Ello permite que las audiencias conozcan el lado sentimental de los mandatarios y candidatos y así generar empatía con la ciudadanía.

De acuerdo con Wideman (2017), las primeras damas en su papel de escoltas son mostradas como un complemento oposicional a sus maridos, bajo el precepto de que ellos encarnan el liderazgo masculino y ellas los roles tradicionales de las mujeres como la compasión y el cuidado maternal (Widlak; Pont-Sorribes; Guillamet-Lloveras, 2016; Van-Wyk, 2017). De esta manera, los roles de ambos se complementan con el fin de generar autoridad y empatía en un mismo paquete presidencial.

En términos generales, el frame presenta poco apego a la esfera política cuando la cónyuge sólo acompaña al mandatario, como lo han documentado los análisis de cobertura de Laura Bush y Hillary Clinton en revistas (Wachai, 2005), las noticias sobre Michelle Obama en diarios (White, 2011) y el estudio histórico del tratamiento informativo de primeras damas estadounidenses (Stoltz, 2013).

\section{b) Anfitriona de la nación}

Si el frame de escolta presidencial mediatiza a las primeras damas como esposas y madres, aquí el papel que juegan es el de la mujer que atiende su casa. De esta manera, las cónyuges presidenciales son encuadradas como anfitrionas nacionales cuando se encargan de la residencia del poder Ejecutivo (Gutin, 1989).

En este aspecto, las principales labores cubiertas por los medios son organizar cenas formales, recibir visitantes extranjeros, seleccionar menús, preparar planos de asientos, decorar y entretener a los allegados del presidente, entre otras actividades donde las primeras damas demuestren su creatividad como hospedantes (O'Connor; Nye; Van-Assendelft, 1996; Beasley, 2005). De acuerdo con Van-Wyk (2017), en dichos eventos ellas deben vestirse de forma impecable, permanecer en bajo perfil y destacar por su desenvolvimiento social con el fin de dejar una buena impresión en las visitas. En ese sentido, los medios les atribuyen características de servicio como ser sonriente, atenta y cariñosa (Widlak; Pont-Sorribes; Guillamet-Lloveras, 2016).

Para Matějčková (2019), el centrar los mensajes en dichos aspectos, respalda y fortalece la tradición, en tanto las aleja de la toma de decisiones importantes y las ubica en las funciones de un ama de llaves. Este encuadre fue encontrado en la cobertura informativa de Barbara y Laura Bush, así como en Michelle Obama (Wachai, 2005; Li, 2015; Karlsdóttir, 2015; Paul; Perreault, 2018).

\section{c) Altruista}

El voluntariado y la beneficiencia son actividades que históricamente han sido lideradas por mujeres, ya que se tratan de tareas que tienen impregnadas el ser-para-otros. Es por ello que algunas primeras damas optan por presidir organizaciones nacionales e internacionales para la defensa de causas sociales en temáticas como medio ambiente y desarrollo social (Erickson; Thomson, 2012).

También son parte de este encuadre las acciones donde las primeras damas conviven con grupos marginados. Winfield y Friedman (2003) señalan que es recurrente encontrar notas sobre almuerzos con víctimas de guerras y desastres naturales tales como huérfanos, personas sin hogar, desahuciados, entre otros. A esta función, Beasley (2005) la reconoce como de consolación, la cual se expone con mayor medida en escenarios de crisis dentro de una nación necesitada de apoyo moral. Esto último concuerda con Matějčková (2019), quien explica que una de las funciones de la primera dama es equilibrar las situaciones difíciles y eventos trágicos. El papel de Laura Bush como consoladora de las víctimas de los atentados del 9/11 en Nueva York es evidencia de este encuadre (McBride, 2016).

Las tareas de activismo y beneficencia, de acuerdo con Van-Wyk (2017), son otorgadas a las primeras damas porque complementan las labores del presidente, éste actúa desde el individualismo en la toma de decisiones políticas y ella labora a partir de socializar con el pueblo, bajo el supuesto de que al ser mujeres cuentan con una conciencia social innata. 
En Estados Unidos se encontraron noticias sobre acciones caritativas y de altruismo en los casos de Laura Bush, Cindy McCain y Michelle Obama. La primera fue encuadrada como altruista a partir de sus visitas a Afganistán donde promovió la educación para las mujeres (Wachai, 2005); McCain cuando viajó a Vietnam para apoyar a niños nacidos con deformidades faciales durante la campaña presidencial de su marido (Shoop, 2010); mientras que Michelle Obama a través de su proyecto Let girls learn promueve la educación de las niñas a nivel mundial (Smith; Carlin, 2016). En este mismo frame se encuentran noticias sobre las primeras damas sudafricanas que apoyan a ciudadanos con VIH (Van-Wyk, 2017) y las esposas de los presidentes de partido en Gran Bretaña, involucradas en diversas organizaciones no gubernamentales de apoyo a la infancia (Higgins; Smith, 2013).

\section{d) Directora de un organismo o proyecto}

Dentro de las funciones no tradicionales, los medios cubren a las primeras damas cuando lideran un proyecto durante la gestión de su esposo, el cual puede ser complementario o no con la agenda del presidente y con diferentes matices político legales (O'Connor; Nye; Van-Assendelft, 1996; Winfield, 1997). Este encuadre, por tanto, hace referencia a los cargos que históricamente concede un país a sus primeras damas o a los proyectos que deciden encabezar. Ellas se involucran en la arena pública al dirigir grupos de trabajo por medio de una oficina o despacho cercana o dependiente de presidencia (Watson, 1997). Dichas responsabilidades y programas son seguidas muy de cerca por los medios.

El dirigir un organismo o proyecto supone una actividad que se desmarca de la tradición, por lo que en los años noventa fue catalogada como tarea de las cónyuges presidenciales modernas (Watson, 1997). Sin embargo, los tipos de temas que cabildean y presiden suelen ser de corte social y no de política dura (Colton, 2016; Van-Wyk, 2017; Matějčková, 2019), lo cual se debe, de acuerdo con Guerrero-Valencia (2015), a una construcción política del género que hace que su agenda se vuelque hacia temas de mujeres, familia e infancia, responsabilidades que tienen embebidas una domesticidad tradicional (Mayo, 2000).

La investigación de Shah (2015) concluye que los proyectos de salud de Hillary Clinton y la campaña contra obesidad infantil de Michelle Obama fueron los temas más cubiertos por la prensa cuando se desempeñaron como primeras damas. Lo anterior apunta a que los medios refuerzan la expectativa de que las cónyuges presidenciales adopten un proyecto o causa sobre el cual reportar.

\section{e) Funcionaria política}

Cuando los medios publican mensajes donde las primeras damas ofrecen su punto de vista acerca de cómo debe realizarse una política, se dice que son encuadradas como funcionarias políticas. Las primeras investigaciones sobre una primera dama con acciones politizadas principalmente se referían a la difusión de la plataforma de su esposo en la arena pública (Kellerman, 1978; Gutin, 1989). Asimismo, los estudios consideraban que ellas eran unos personajes importantes en la carrera de los presidentes, en tanto que les asesoraban y aconsejaban en sus decisiones (Watson, 1997; Borrelli, 2002).

Sin embargo, trabajos recientes señalan que el encuadre de funcionaria política es cada vez más independiente de las agendas de sus esposos (Colton, 2016), lo cual ha servido para complementar tareas. Asimismo, el tipo de temas hacia los cuales emite una opinión ya no son los tradicionales de las mujeres, sino que se tratan de asuntos considerados masculinos como política exterior, seguridad y macroeconomía (Widlak; Pont-Sorribes y Guillamet-Lloveras, 2016). Su opinión también es importante al momento de declarar sus preferencias políticas y así influir en nominaciones, campañas y elecciones (O'Connor; Nye; Van-Assendelft, 1996).

Además de verter sus opiniones en los medios, otra función destacada en este encuadre es participar en reuniones del gabinete presidencial (Winfield; Friedman, 2003) y cabildear políticas públicas, de forma que participan en la elaboración de leyes (Matějčková, 2019). Uno de los casos con mayor resonancia es el de Hillary Clinton cuando presentó ante el Congreso de los Estados Unidos su reforma a los programas de salud, lo cual trascendió a todos los roles tradicionales de las primeras damas (Karlsdóttir, 2015; Shah, 2015).

De acuerdo con Gonnella-Platts y Fritz (2017), las primeras damas poseen una oportunidad única de traspasar los límites establecidos por la tradición, para acercarse a una ciudadanía de diferentes estratos con los cuales negociar asuntos de importancia nacional. Y es que la red de contactos que las envuelve, entre los que se encuentra el gabinete presidencial, vicepresidente, legisladores, medios, empresarios, entre otros, las capacita para generar un mayor impacto en la gestación de políticas públicas (Eweka, 2020). No obstante, este tipo de actitudes no esperadas de la esposa de un mandatario suelen generar un abordaje mediático con tonalidad negativa (Butler, 2013; Harmer, 2016) y una resistencia por parte de las audiencias (Vigil, 2014; Elder; Frederick, 2017). Los medios privilegian los roles tradicionales de las primeras damas sobre sus contribuciones públicas y políticas (Kitsch, 2017).

Los medios también encuadran a las primeras damas como funcionarias políticas cuando sustituyen a sus esposos en actividades públicas (Wekkin, 2000). Para Erickson y Thomson (2012) y Van-Wyk (2017), esto ocurre principalmente 
en eventos internacionales donde acuden en calidad de diplomáticas, emisarias culturales y embajadoras de la buena voluntad.

Este papel internacional que desempeñan las primeras damas las acerca a lo que Nye (2011) denomina como poder blando, el cual se refiere a la habilidad de un país de persuadir en otros a través de narrativas de cooperación con el fin de obtener los resultados que desean. Zhang (2017) retoma este concepto para asegurar que las cónyuges presidenciales atraen al mundo con su cultura y sus valores. Por tanto, cuando una primera dama visita otro Estado, los medios la encuadran como la representante ideal de una mujer de ese país al exponer su cultura y su nación (Finneman; Thomas, 2014).

De acuerdo con Smith (1997), las primeras damas asisten a eventos en lugar de sus esposos principalmente durante escenarios tensos, de crisis o guerra, donde tratarán de resolver la problemática sin poner en riesgo la popularidad del mandatario. De esta manera, es importante contextualizar si el encuadre noticioso al que se asemeja obedece a cierta estrategia política, ya que se ha encontrado que los niveles de aprobación de las primeras damas pueden ser transferidos como capital político para el presidente (MacManus; Quecan, 2008; Marrs, 2018).

Es así como el encuadre de funcionaria política engloba en mayor medida las acciones politizadas no tradicionales a través de intervenir en temas de política dura, ya sea al emitir su opinión o al participar de manera activa. Hillary Clinton resultó con dicho encuadre en los estudios de cobertura de la revista Time (Wachai, 2005), Washington Post (Butler, 2013) y The New York Times (Shah, 2015); aunque con menor incidencia, también fue encontrado en el abordaje de Michelle Obama en The New York Times, Washington Post, The Wall Street Journal (Shoop, 2010), la revista Time Mortensen (2015) y la prensa china (Li, 2015).

\section{f) Celebridad}

La cobertura periodística de asuntos políticos se encuentra en una tendencia hacia el infoentretenimiento, donde se mezcla información política y de entretenimiento con el fin de simplificar y estereotipar acciones y actores políticos, lo cual se traduce en mayores ventas (Sánchez-Zepeda; Echeverría-Victoria, 2018). En ese sentido, las primeras damas suelen ser encuadradas como celebridades cuando se trivializan sus acciones al centrarse en su apariencia, es decir, su vestuario, peinado y maquillaje (Kellerman, 1978; Wekkin, 2000; Winfield; Friedman, 2003; Sullivan, 2018; ÁlvarezMonsiváis, 2019), pero también su vida personal como religión, grados académicos, profesión, edad, número de hijos, quiénes son sus padres, entre otros datos (Gutin, 1989; O'Connor; Nye; Van-Assendelft, 1996; Borrelli, 2002).

Si bien este tipo de cobertura trivializa las acciones de las cónyuges presidenciales, puede ser benéfico para los mandatarios, ya que cuentan con un foco mediático constante que se presenta como una oportunidad de exponer planes de gobierno (Beasley, 2005). El darse a conocer como famosas también les acerca a otras celebridades para tener mayor exposición en los medios, lo que les permite llegar a más audiencias (Widlak; Pont-Sorribes; Guillamet-Lloveras, 2016). Taglianetti (2019) coincide con lo anterior en tanto plantea que las primeras damas en su papel de celebridades aprovechan las innovaciones de los medios para atraer atención mediática. Menciona como ejemplos a Florence Harding cubierta por la prensa, Jacqueline Kennedy en televisión y Michelle Obama en redes sociales, cada una retratada por el medio con mayor penetración de su época.

La mayoría de las noticias suelen ser datos sobre sus hijos, vida personal y controversias, trabajo doméstico, moda, raza, imagen física, embarazos, cocina, joyería, diseñadores, valores familiares, viajes, entre otros. Lo anterior se ha encontrado en noticias estadounidenses (Kalyango; Winfield, 2009; Zeldes, 2009; Shoop, 2010; White, 2011; Butler, 2013; Zamora-Medina; Berná-Sicilia; Martínez-Martínez, 2014; Li, 2015; Matthews; Chaney; Opiri, 2015; Fernández-Fernández, 2017; Rall et al., 2018), europeas (Higgins; Smith, 2013; Harmer, 2016; Widlak, 2017; Gejdošová, 2019) y chinas (Li; Yin, 2018).

Stoltz (2013) describe cómo Pat Nixon se posicionó en la Convención Republicana a favor del acceso de las mujeres a cargos de elección popular y a la Suprema Corte; mientras que lo remarcado por los medios sobre ese evento fue el de su figura elegante y prototípica. En ese sentido, el enfoque a este tipo de temas despolitiza y domestica al papel de las primeras damas en tanto que elude la importancia de su poder político y las ubica en un ámbito corpóreo (Keohane, 2017).

A partir de esta definición de encuadres y los antecedentes de investigación se planteó la siguiente pregunta:

PI1: ¿Cuáles fueron los encuadres noticiosos más reiterados en las primeras damas del corpus?

Debido a que se ha encontrado que los encuadres menos tradicionales tienen mayor prominencia en primeras damas con credenciales profesionales o académicas en la política (Eksterowicz; Roberts, 2004; Butler, 2013; Karlsdóttir, 2015; Li, 2015; Mortensen, 2015; Shah, 2015), se ha postulado la siguiente hipótesis:

H1: El encuadre político será más evidente en las primeras damas con una trayectoria política previa

\subsection{Factores explicativos de los encuadres}

El sexo del reportero y el espectro político del medio suelen considerarse como variables de las empresas de comunicación para explicar la reiteración de encuadres. Sobre la primera variable, los estudios señalan que si un varón firma la nota, las mujeres políticas obtienen un abordaje despolitizado basado en el rol tradicional de éstas en la sociedad (Aday; 
Devitt, 2001; Cassidy, 2012; Whalen, 2016). Lo anterior puede deberse a que los estudios han encontrado que las reporteras tienden a dar un enfoque más noticioso hacia las problemáticas de género (Wagner, 2017; Tiscareño-García; Miranda-Villanueva, 2020). Sin embargo, otro bloque de trabajos indica que las reporteras son las que buscan un corte más humano y de apariencia, sin entrar en temas de política dura (Vos, 2013; Conroy et al., 2015). Así, no parece haber consenso en esta variable por lo que es preferible continuar su exploración.

Sobre el espectro político del medio, Cassidy (2012) señala que los canales de paga estadounidenses de corte conservador tienden a despolitizar el papel de las mujeres, para acercarse al abordaje desde el género, lo cual resultó opuesto en la televisión liberal. No obstante, de acuerdo con Biachi (2013) y Wallström (2017), más que la ideología del medio, lo que está en juego es la similitud ideológica del medio con la plataforma política del presidente en turno. Así, mientras más similitud, mayor politización de las figuras de mujeres en política. Lo anterior había sido considerado por Matthes (2012) quien expuso que los encuadres son conjuntos de argumentos propuestos tanto por medios opositores como por defensores. Considerado lo anterior, se generó la siguiente pregunta de investigación:

PI2: ¿Se detectó un tratamiento informativo diferente de acuerdo con la línea editorial del medio y con el sexo del reportero que firmó la noticia?

Para contestar dicha pregunta, se generaron dos hipótesis, una por cada variable:

H2: Los diarios con similitud ideológica al gobierno en turno tienden a la politización en la cobertura de primeras damas

H3: Los mensajes periodísticos firmados por mujeres reporteras tienden a cubrir a las primeras damas a partir de encuadres politizados

Sobre de qué manera participan las primeras damas en la noticia, se ha encontrado que las mujeres registran menor frecuencia de citas directas que cualquier varón en política. Existe prueba de ello en la prensa estadounidense (Aday; Devitt, 2001), latinoamericana (Llanos, 2014), europea (Humprecht; Esser, 2017) e incluso en estudios comparativos entre diversos países (Haraldsson; Wängnerud, 2019). Por tal motivo, se estableció la siguiente pregunta e hipótesis de investigación a la luz de los encuadres previamente establecidos:

PI3: ¿En cuáles encuadres participaron las primeras damas a través de citas directas?

H4: Los diarios recurren a la voz de las primeras damas en encuadres politizados

\subsection{Primeras damas en México, Argentina y Estados Unidos}

En México, de acuerdo con Aguilar-Castro (2006), a las primeras damas se les ha pedido que representen y materialicen, a través de diferentes proyectos, los ideales de la familia, entendida como la institución abstracta y perenne que reproduce pautas de comportamiento aceptables. En ese sentido, la autora subraya que fue Beatriz Velasco (1946-1952), esposa de Miguel Alemán, la primera cónyuge presidencial que debió rendir informe anual de su programa de entrega de desayunos. Las siguientes esposas presidenciales encabezaron asociaciones e instituciones de apoyo a la infancia, que derivaron en lo que actualmente es el Sistema Nacional para el Desarrollo Integral de la Familia (DIF) fundado en 1977 y que hasta 2018 era dirigido por cada primera dama en funciones (Vargas, 2018).

Por su parte, las cónyuges presidenciales panistas se distinguieron por militar en el partido antes de obtener el puesto (infobae, 2020). Marta Sahagún (2001-2006) fue candidata a presidenta municipal de Celaya (1995) y Margarita Zavala (2006-2012) ocupó una diputación nacional (2003-2006). Por otro lado, la prensa mexicana siguió muy de cerca los escándalos mediáticos de la auditoría a Sahagún por recibir millonarios donativos a través de su Fundación Vamos México (Villamil, 2004); Zavala por presuntamente desligar de responsabilidades a su prima Marcia Gómez del Campo en el incendio de la Guardería ABC (Zepeda, 2012); y Angélica Rivera (2012-2018) por la adquisición de un inmueble millonario de la mano de Grupo Higa, una constructora beneficiada por licitaciones durante el gobierno de Enrique Peña Nieto (Lizárraga et al., 2015).

Las primeras damas argentinas, si bien no ocupan cargo u oficina, han tenido especial injerencia en la política, lo que obliga a plantearse las implicaciones de éstas en una estructura formal de gobierno en la que no estaban contempladas (Barry, 2018). Eva Duarte (1946-1952) impulsó la ley para que las mujeres pudieran votar y ser votadas y fundó el Partido Peronista Femenino; en tanto Isabel Perón (1973-1974), la última esposa de Juan Domingo, fue vicepresidenta del país y, al quedar viuda, fungió como presidenta (Amato, 2019). Mientras que Hilda Duhalde (2002-2003) y Cristina Fernández (2003-2007) lograron puestos legislativos antes y después de ser primeras damas (Guerrero-Valencia y Arana-Araya, 2019).

Por otro lado, algunas cónyuges han obtenido una gran repercusión mediática. Tal es el caso de Silvia Martorell (19631966), quién realizó una entrevista para el periodista Tomás Eloy Martínez, que es documentada como parte de la guerra sucia que terminó con el derrocamiento del presidente Arturo Umberto Illia (Molteni, 2016). Asimismo, los conflictos matrimoniales entre el presidente Carlos Menem (1989-1999) y su esposa Zulema Yoma fueron seguidos por la prensa, entre los cuales figura el desalojo de la primera dama de la casa presidencial (Ares, 1990). En contraparte, María Lorenza Barreneche (1983-1989) e Inés Pertiné (1999-2001) tuvieron una discreta participación pública durante los mandatos de sus esposos (Amato, 2019). 
Inaugurada en 1977, la oficina de la primera dama de los Estados Unidos es dependiente de la oficina ejecutiva del presidente y contempla una partida prepuestaria con un equipo de colaboradores (Borrelli; Tenpas; Wright, 2017). El proyecto se define de acuerdo con los intereses de la primera dama en funciones. Nancy Reagan (1981-1989) tuvo como estandarte la prevención de drogas por medio del eslogan Just say no (Mackey-Kallis; Hahn, 1991); Laura Bush (20012009) siguió los pasos de su suegra Barbara (1989-1993) con el proyecto Ready to ready, ready to learn, cuyo fin era reducir los índices de analfabetismo (Bush, 2002); Michelle Obama (2008-2016) a través de la campaña Let's move! buscó disminuir los índices de obesidad infantil (Jackson, 2012); mientras que Melania Trump (2016-2020) ha promovido la iniciativa Be best para erradicar el ciberacoso (Zorthian, 2016). Aunque sin una campaña, las cónyuges presidenciales anteriores a Reagan tomaron para sí proyectos relacionados con el acceso a la salud mental, búsqueda de la igualdad de género, asistencia social para los estratos económicos bajos y protección al medio ambiente.

Hillary Clinton (1993-2001) es considerada como la cónyuge presidencial con más atribuciones políticas de Estados Unidos al centrarse en la reforma de salud, la cual defendió ante el Congreso de aquel país (Corrigan, 2000). Mientras que Jacqueline Kennedy (1961-1963) es recordada como "la primera dama más vista en el mundo" al ganar atención de medios nacionales y extranjeros por su vestimenta que imponía moda y la redecoración de la Casa Blanca (Taglianetti, 2019).

\section{Método}

Considerados los aportes teóricos y antecedentes de investigación, se decidió realizar un análisis de contenido en noticias de diarios generalistas sobre primeras damas. Dicha técnica de investigación se justificó en que permite generar inferencias reproducibles, sistemáticas y válidas en un contexto dado (Krippendorff, 1990), además que es la más utilizada por las investigaciones que se enfocan en framing (Piñeiro-Naval; Mangana, 2018).

\subsection{Casos de estudio}

Las nueve primeras damas que participaron en la conformación de la muestra fueron clasificadas en tres grupos. Los dos primeros obedecieron a la taxonomía de Guerrero-Valencia y Arana-Araya (2019), quienes las ubican como activas cuando tuvieron experiencia política previa al cargo protocolar; mientras que son novatas las ajenas al ámbito político antes de ser primeras damas. Durante el presente ejercicio, las políticas activas también cumplieron el requisito que después de su período como primeras damas buscaron la presidencia de su país, lo que las podría acercar aún más a un encuadre politizado. Por tanto, a las integrantes de este grupo se les denominó políticas expertas para diferenciarlas de las activas. La importancia de esta distinción entre expertas y novatas es que en la conformación de encuadres sobre primeras damas intervienen sus antecedentes personales, como estudió Eksterowicz y Roberts (2004).

El tercer grupo fue el de las actuales, en el que se consideraron las cónyuges presidenciales que al momento de realizada la investigación se encontraban en funciones. La propuesta de analizar a las actuales se sostiene en la conclusión de Colton (2016) donde el paso de las actividades tradicionales a modernas de una primera dama no es lineal con el tiempo, lo cual puede ser sustentado en los estudios que analizan a más de una primera dama y no indican cambios hacia una cobertura menos tradicional (Butler, 2013; Stoltz, 2013; Karlsdóttir, 2015;

Harmer, 2016; Van-Wyk, 2017; Widlak, 2017; Rall et al., 2018). Aunado a ello, Burns (2004) plantea que en los países donde existe el antecedente de una primera dama que irrumpió un orden tradicional para inmiscuirse en política suele dar como resultado a una sucesora que trae consigo un retorno a las costumbres para así generar nuevos roles tradicionales, por ejemplo, la tríada Barbara Bush (tradicional) - Hillary Clinton (moderna) - Laura Bush (nueva tradición). El estudio de las actuales, por tanto, se justifica en vislumbrar cuáles serán los encuadres en la cobertura de las nuevas primeras damas en países donde ya ostentó el puesto al menos una política experta.

Se seleccionaron tres países del continente americano para analizar: Argentina, Estados Unidos y México. Esta decisión se justificó en que dichos países cuentan con estos tres tipos de primeras damas en los últimos 30 años por lo que la oportunidad de recuperar las noticias que las abordaron era mayor. Los otros países de la región que cumplieron con todos los requisitos anteriores fueron Guatemala y Guyana, pero se desestimaron debido a la dificultad para conseguir las noticias.

Las políticas expertas elegidas para cada uno de los países fueron Cristina Fernández (2003-2007), Hillary Clinton (19932001) y Margarita Zavala (2006-2012), quienes fungieron como primeras damas durante las presidencias de Néstor Kirchner, Bill Clinton y Felipe Calderón, respectivamente. Se explica que tuvieron un antecedente político anterior debido a que fueron miembros de su partido político, así como diputadas previo a que su marido ocupara el poder Ejecutivo de su país. Además, como se mencionó anteriormente, las tres se candidatearon a la presidencia: Fernández obtuvo en dos ocasiones el cargo en 2007 y 2011; Hillary perdió en las elecciones estadounidenses de 2016; mientras que Zavala retiró su candidatura a media campaña en 2018. 
Las cónyuges presidenciales novatas fueron la empresaria textil argentina Juliana Awada (2015-2019), esposa de Mauricio Macri; la poeta estadounidense Laura Bush (2001-2009) quien ocupó el cargo protocolar al estar casada con George W. Bush; y la actriz mexicana Angélica Rivera (2012-2018), ex esposa de Enrique Peña Nieto.

El último grupo la conforman las actuales primeras damas de esos países, es decir, en Argentina, la periodista Fabiola Yáñez (2019); en Estados Unidos, la modelo Melania Trump (2016); y en México la académica Beatriz Gutiérrez Müller (2018). Ellas son parejas de los mandatarios Alberto Fernández, Donald Trump y Andrés Manuel López Obrador, respectivamente.

\subsection{Diarios que conformaron la muestra}

El medio elegido fue el periódico en su versión impresa, cuyos números se recuperaron a través de Factiva, Lexis Nexis, ProQuest y los archivos web de los diarios. Estos medios debieron ser de circulación nacional y encontrarse entre los cuatro diarios con mayor tiraje, lo cual fue constatado en el Instituto Verificador de Circulaciones (2019) en Argentina, la agencia Cision Media Research (2019) para Estados Unidos y el catálogo de medios del Instituto Nacional Electoral (2019) en México. Así, los periódicos reunieron los requisitos necesarios para asegurar que llegan a gran cantidad de lectores.

Otro aspecto reparado sobre los medios fue el espectro ideológico. De acuerdo con los trabajos analizados que ofrecen un catálogo de medios clasificados por orientación política (Lawson, 2002; Ho; Quinn, 2008; Durán-Gracia, 2009; Brussino et al., 2011; Rodelo; Muñiz, 2017), es posible ubicar a los medios como liberales o de izquierda y conservadores o de derecha. De esta manera, se seleccionó uno de cada extremo del espectro para cada país. Los diarios liberales o de izquierda fueron el argentino Página/12, el estadounidense The New York Times y el mexicano La jornada. Los periódicos conservadores o de derecha escogidos para análisis resultaron La nación, The Wall Street Journal y Reforma.

Posterior a esta selección, se propuso una clasificación alterna a este espectro a través de la similitud ideológica del medio con la del partido político que llevó al poder al esposo de la primera dama en turno. Lo anterior se realizó como lo sugieren Biachi (2013) y Wallström (2017). De esta forma, los periódicos liberales o de izquierda tendrían mayor similitud con el Partido Justicialista argentino, el Partido Demócrata estadounidense y el Partido Morena en México.

Por otro lado, los conservadores o de derecha resultarían similares ideológicamente a los partidos Propuesta Republicana en Argentina, Partido Republicano en Estados Unidos y Partido Acción Nacional en México. Únicamente el Partido Revolucionario Institucional mexicano obtendría a ambos medios con una disparidad ideológica al ser de centro. También hay que hacer notar que se habla de similitud ideológica y no de afinidad ideológica ni mucho menos de apoyo evidente del medio al partido. Se habla de similitud ideológica para registrar que ambos, partido y diario, se ubican en el mismo espacio del espectro, lo cual no quiere decir que el diario coincida y esté de acuerdo en la forma de ejecutar la política del gobierno.

\subsection{Selección de la muestra}

La unidad de análisis fue el género informativo de noticia, el cual, de acuerdo con Benavides y Quintero (2005) consiste en la información sobre una ruptura del flujo normal de eventos cuya vigencia es efímera y veloz. El trabajo no incluyó reportajes ni géneros de opinión; tampoco galerías de fotos, vídeos ni infografías sin descripción textual.

Para seleccionar las noticias que formarían parte de la muestra se utilizaron palabras clave que incluyeran todas las posibilidades en las que un medio puede hacer alusión a las primeras damas de cada uno de los países, como su nombre, apellido de casada y soltera, "primera dama", "first lady" y "cónyuge presidencial". Estas palabras debieron aparecer en el título o primer párrafo (lead), porque así se entiende que la noticia versa sobre la primera dama. Dicho filtro depuró las notas donde simplemente se mencionaba su nombre sin una acción o descripción que permitiera clasificarlas en alguno de los encuadres.

Para conformar las noticias para análisis se utilizó la técnica de la semana compuesta aleatoria con salto sistemático (Lozano, 1994; Valenzuela; Correa, 2006; Soengas-Pérez, 2007). Ésta consistió en construir una semana con un lunes, un martes, un miércoles, etcétera, por cada año gestión de la primera dama. Si el lunes seleccionado de forma aleatoria no generó una noticia sobre la primera dama, se realizó un salto sistemático de ocho días hasta el siguiente lunes inmediato, cosa que se repetía hasta registrar una noticia.

Tabla 1. Períodos analizados y técnica de recolección de noticias

\begin{tabular}{|l|l|l|l|}
\hline \multicolumn{1}{|c|}{ Primera dama } & \multicolumn{1}{|c|}{ Clasificación } & \multicolumn{1}{c|}{ Período analizado } & \multicolumn{1}{c|}{ Técnica de recolección } \\
\hline Cristina Fernández & Política experta & $25 / 05 / 2003$ al 10/12/2007 & Semana compuesta \\
\hline Juliana Awada & Novata & $10 / 12 / 2015$ al 10/12/2019 & Semana compuesta \\
\hline Fabiola Yáñez & Actual & $12 / 08 / 2019$ al 19/03/2020 & Censo \\
\hline Hillary Clinton & Política experta & $20 / 01 / 1993$ al 20/01/2001 & Semana compuesta \\
\hline Laura Bush & Novata & $20 / 01 / 2001$ al 20/01/2009 & Semana compuesta \\
\hline Melania Trump & Actual & $21 / 07 / 2016$ al 30/04/2017 & Censo \\
\hline Margarita Zavala & Política experta & $01 / 12 / 2006$ al 01/12/2012 & Semana compuesta \\
\hline Angélica Rivera & Novata & $01 / 12 / 2012$ al 01/12/2018 & Semana compuesta \\
\hline Beatriz Gutiérrez & Actual & $30 / 03 / 2018$ al 10/03/2019 & Censo \\
\hline
\end{tabular}


Lo anterior aplicó únicamente para las primeras damas cuya gestión finalizó. Para el grupo de las actuales se realizó un censo de noticias ya que el tiempo de gestión era relativamente corto. Las noticias censadas debieron aparecer desde el período de campañas electorales hasta los primeros 100 días de gobierno de su marido, mismo tiempo analizado por Shoop (2010), Butler (2013) y Fernández-Fernández (2017). Los años analizados se representan en la tabla 1. Considerado todo lo anterior, se analizaron $\mathrm{N}=390$ noticias, repartidas en $\mathrm{n}=86$ en Argentina, $\mathrm{n}=161$ en Estados Unidos y $n=143$ en México.

\subsection{Manual de codificación}

Para el examen de este corpus representativo de análisis se redactó un libro de códigos con tres categorías de variables nominales:

- Sexo del reportero $\left(\alpha_{k}=0,94\right)$ : 1=hombre u hombres, $2=$ mujer o mujeres, $3=$ mixto, staff, redacción o no identificado.

- Encuadre noticioso $\left(\alpha_{k}=0,82\right)$ : 1=escolta presidencial, 2=anfitriona nacional, 3=altruista, 4=celebridad, 5=directora de un organismo o proyecto, $6=$ funcionaria política, $7=$ =otro/ninguno.

- Citas directas $\left(\alpha_{k}=0,98\right): 1=$ presencia de citas directas de las primeras damas, $0=s i n$ presencia de citas directas.

A estas categorías hay que sumar las relacionadas con el espectro político y línea editorial, así como fecha, diario del cual fue obtenido, cónyuge presidencial en la noticia y tipo de primera dama.

En el caso del encuadre noticioso, los codificadores pudieron recurrir como referencia al menos a cinco atributos y ejemplos para cada uno con el fin de asegurar una codificación con claridad. Dichas descripciones se crearon a partir de los trabajos anteriormente revisados, es decir, de manera deductiva, pero también de forma inductiva a partir de los casos de la prueba piloto.

Con ayuda del manual, los codificadores seleccionaron qué encuadre estuvo latente en la noticia, esto es, el constructo que es inferido en el mensaje a partir de una definición conceptual (Igartua, 2012). A pesar de que cada uno de los frames establecidos tienen descripciones propias, podría ocurrir que una misma nota fuera clasificable en más de uno a lo largo del texto. En esos casos se les solicitó a los codificadores seleccionar únicamente el que estuvo latente en el título o primer párrafo. Lo anterior se decidió ya que es precisamente en estos elementos donde el periodista sitúa el aspecto más relevante y nuclear de la historia y son los más susceptibles de ser leídos por los consumidores (Benavides; Quintero, 2005; Bleich et al., 2015). De igual forma, las investigaciones anteriores enfatizan que los encuadres dominantes suelen estar determinados por el título y primer párrafo (Weaver; Lively; Bimber, 2009; Catalán-Matamoros; Peñafiel-Saiz, 2019).

La recogida de la información se realizó en dos períodos, del 1 al 31 de agosto de 2018; y del 17 de abril al 2 mayo de 2020. Para conocer la fiabilidad del instrumento de codificación, se calculó sobre las respuestas de cuatro codificadores a través del alfa de Krippendorff (Krippendorff, 2017; Piñeiro-Naval; Morais, 2019). Para ello se seleccionó de manera aleatoria un $10 \%$ de las noticias de cada primera dama. Como pudo observarse anteriormente, las tres categorías resultaron con una fiabilidad satisfactoria $\left(\alpha_{k}>0,80\right)$, cuyo promedio fue de $M\left(\alpha_{k}\right)=0,91$.

\section{Resultados}

Para contestar la primera pregunta de investigación relacionada con cuáles fueron los encuadres más recurrentes en las noticias analizadas se presenta la tabla 2. En ella es posible observar que el frame con mayor incidencia fue el de funcionaria política, que se presentó en el 31\% de las noticias. Cristina Fernández obtuvo el mayor registro con el $60 \%$ en dicho marco noticioso.

El de menor presencia fue el de altruista con el $6 \%$ de mensajes estudiados, que resultó con mayor prominencia en la actual primera dama de Argentina, Fabiola Yáñez (15\%). Juliana Awada, del mismo país, fue la cónyuge presidencial que recibió un tratamiento periodístico notorio a través del encuadre de escolta presidencial con el 64\% de incidencia.

El frame de anfitriona nacional que incluye la recepción de mandatarios externos fue encontrado en mayor proporción en la información noticiosa dedicada a Margarita Zavala (25\%). El encuadre de celebridad, agregado a los teorizados por Winfield (1997), estuvo presente de forma evidente en la cobertura de Hillary Clinton (36\%) y Angélica Rivera (36\%).

El último marco informativo relacionado con la dirección de un organismo o proyecto se halló en la cónyuge presidencial actual de México, Beatriz Gutiérrez Müller, en el 37\% de los casos. Laura Bush (39\%) y Angélica Rivera (40\%) fueron mostradas como funcionarias políticas a pesar de no poseer formación previa en ese ámbito.

Para ahondar en los resultados sobre los encuadres más recurrentes, se agruparon los resultados de acuerdo con la tipología de primeras damas, esto es, si tenían un pasado político (política experta) o si se tratan de novatas en la política; así como un tercer tipo en el que se clasificaron las cónyuges del Ejecutivo que actualmente ocupan el cargo. La hipótesis que se buscó comprobar fue:

H1: El encuadre político será más evidente en las primeras damas con una trayectoria política previa 
Tabla 2. Encuadres noticiosos en la cobertura de las primeras damas del estudio

\begin{tabular}{|c|c|c|c|c|c|c|c|}
\hline Primera dama & $\begin{array}{c}\text { Escolta } \\
\text { presidencial }\end{array}$ & $\begin{array}{c}\text { Anfitriona } \\
\text { nacional }\end{array}$ & Altruista & Celebridad & $\begin{array}{l}\text { Directora de } \\
\text { un organismo }\end{array}$ & $\begin{array}{c}\text { Funcionaria } \\
\text { política }\end{array}$ & Total \\
\hline Cristina Fernández & 0 & 13 & 2 & 25 & 0 & 60 & $\begin{array}{c}100 \% \\
(n=40)\end{array}$ \\
\hline Juliana Awada & 64 & 9 & 3 & 18 & 3 & 3 & $\begin{array}{l}100 \% \\
(n=33)\end{array}$ \\
\hline Fabiola Yáñez & 31 & 0 & 15 & 8 & 8 & 38 & $\begin{array}{c}100 \% \\
(n=13)\end{array}$ \\
\hline Hillary Clinton & 7 & 15 & 8 & 36 & 6 & 28 & $\begin{array}{c}100 \% \\
(n=88)\end{array}$ \\
\hline Laura Bush & 16 & 2 & 8 & 31 & 4 & 39 & $\begin{array}{c}100 \% \\
(n=49)\end{array}$ \\
\hline Melania Trump & 21 & 4 & 4 & 34 & 8 & 29 & $\begin{array}{c}100 \% \\
(n=24)\end{array}$ \\
\hline Margarita Zavala & 13 & 25 & 6 & 18 & 15 & 23 & $\begin{array}{c}100 \% \\
(n=71)\end{array}$ \\
\hline Angélica Rivera & 9 & 0 & 6 & 36 & 9 & 40 & $\begin{array}{c}100 \% \\
(n=53)\end{array}$ \\
\hline Beatriz Gutiérrez & 21 & 5 & 5 & 16 & 37 & 16 & $\begin{array}{c}100 \% \\
(n=19)\end{array}$ \\
\hline Total & $\begin{array}{c}16 \\
(n=62)\end{array}$ & $\begin{array}{c}11 \\
(n=42)\end{array}$ & $\begin{array}{c}6 \\
(n=24)\end{array}$ & $\begin{array}{c}27 \\
(n=107)\end{array}$ & $\begin{array}{c}9 \\
(n=34)\end{array}$ & $\begin{array}{c}31 \\
(n=121)\end{array}$ & $\begin{array}{c}100 \% \\
(n=390)\end{array}$ \\
\hline
\end{tabular}

Nota: En negrita roja se indica el porcentaje más alto de cada encuadre

La tabla 3 muestra que el encuadre de funcionaria política fue el más recurrente en los tres tipos de primeras damas. Sin embargo, las políticas expertas, que incluyen a Fernández, Clinton y Zavala, registraron el mayor porcentaje de noticias con dicho frame (33\%), que si bien no fue un resultado contundente (apenas $3 \%$ más que las políticas novatas), la prueba estadística resultó significativa, $\chi^{2}(10, N=390)=46,47, p=0,000$, con un coeficiente de contingencia de $33 \%$. Por tal motivo es posible aceptar la $\mathrm{H} 1$.

Sin embargo, resulta conveniente analizar otros resultados respecto a los encuadres por tipo de cónyuge presidencial. Por ejemplo, el encuadre de celebridad, si bien se encontró en menor proporción que el de funcionaria política, fue alto en el caso de las políticas expertas (28\%), por lo que este encuadre parece incidir sin importar las trayectorias previas de las esposas de los mandatarios.

Por otro lado, las novatas registraron el $25 \%$ de notas en escolta presidencial, mientras que las políticas expertas únicamente el 7\%. Así, los diarios analizados cubrieron en mayor medida a las novatas por acompañar a sus esposos en eventos; mientras que las expertas recibieron menor cantidad en este rubro, esto es, de forma más independiente de los mandatarios.

Las actuales, en tanto, recibieron una atención más tradicional como las novatas, más que como las expertas. También se registró una tendencia de los medios analizados hacia cubrir los proyectos u organismos que las nuevas primeras damas decidieron encabezar (18\%), en detrimento de lo obtenido por las expertas (8\%) y novatas (6\%).

Tabla 3. Encuadres noticiosos de acuerdo con el tipo de primera dama

\begin{tabular}{|c|c|c|c|c|}
\hline Encuadre & Políticas expertas & Políticas novatas & Actuales & Total \\
\hline Funcionaria política & 33 & 30 & 27 & $\begin{array}{c}31 \\
(n=121)\end{array}$ \\
\hline Celebridad & 28 & 30 & 21 & $\begin{array}{c}27 \\
(n=107)\end{array}$ \\
\hline Escolta presidencial & 7 & 25 & 23 & $\begin{array}{c}16 \\
(n=62)\end{array}$ \\
\hline Anfitriona nacional & 18 & 3 & 4 & $\begin{array}{c}11 \\
(n=42)\end{array}$ \\
\hline Directora de un proyecto & 8 & 6 & 18 & $\begin{array}{c}9 \\
(n=34)\end{array}$ \\
\hline Altruista & 6 & 6 & 7 & $\begin{array}{c}6 \\
(n=24)\end{array}$ \\
\hline Total* & $\begin{array}{c}100 \% \\
(n=199)\end{array}$ & $\begin{array}{c}100 \% \\
(n=135)\end{array}$ & $\begin{array}{c}100 \% \\
(n=56)\end{array}$ & $\begin{array}{c}100 \% \\
(n=390)\end{array}$ \\
\hline
\end{tabular}

${ }^{*} p<0,05$ 
Se elaboraron dos hipótesis con el fin de contestar la segunda pregunta de investigación sobre la detección de un tratamiento informativo de acuerdo con la línea editorial del medio y con el sexo del reportero que firmó la noticia:

H2: Los diarios con similitud ideológica al gobierno en turno tienden a la politización en la cobertura de primeras damas

H3: Los mensajes periodísticos firmados por mujeres reporteras tienden a cubrir a las primeras damas a partir de encuadres politizados

Sobre la H2, como puede revisarse en la tabla 4, los resultados apuntaron que la politización de la cobertura de las cónyuges presidenciales fue más notoria en las noticias de periódicos opuestos ideológicamente al gobierno en turno (34\%). Sin embargo, estos mismos medios fueron los que aportaron la forma menos politizada de las primeras damas, es decir, el encuadre de celebridad en un $32 \%$ de los mensajes periodísticos.
Los encuadres más reiterados fueron funcionaria política (31\%) y celebridad (27\%), los cuales son frames opuestos entre sí, pues uno representa la parte activa en la arena pública, y el segundo la pasiva, en la esfera íntima

Los diarios con similitud ideológica con el presidente en turno registraron una marcada tendencia hacia mostrarlas en lugares más tradicionales como anfitrionas nacionales (18\%) y escoltas presidenciales (17\%). Así, las cónyuges de los mandatarios fueron presentadas por acompañarlos a eventos culturales o por remodelar la casa presidencial.

Debido a que los medios con similitud ideológica evidenciaron aspectos tradicionales en mayor medida que los opositores al gobierno, los cuales tendieron a la politización, la H2 se rechazó. Estos resultados fueron verificados por la prueba $\left.\chi^{2}(10, N=390)=20,41, p=0,001\right)$ que establece una asociación significativa entre la línea editorial y los encuadres.

Tabla 4. Encuadres noticiosos de acuerdo con la línea editorial

\begin{tabular}{|c|c|c|c|}
\hline Encuadre & $\begin{array}{l}\text { Diarios con similitud ideológica } \\
\text { al gobierno }\end{array}$ & Diarios opositores al gobierno & Total \\
\hline Funcionaria política & 26 & 34 & $\begin{array}{c}31 \\
(n=121)\end{array}$ \\
\hline Celebridad & 21 & 32 & $\begin{array}{c}27 \\
(n=107)\end{array}$ \\
\hline Escolta presidencial & 17 & 15 & $\begin{array}{c}16 \\
(n=62)\end{array}$ \\
\hline Anfitriona nacional & 18 & 6 & $\begin{array}{c}11 \\
(n=42)\end{array}$ \\
\hline Directora de un proyecto & 10 & 8 & $\begin{array}{c}9 \\
(n=34)\end{array}$ \\
\hline Altruista & 8 & 5 & $\begin{array}{c}6 \\
(n=24)\end{array}$ \\
\hline Total & $\begin{array}{c}100 \% \\
(n=156)\end{array}$ & $\begin{array}{c}100 \% \\
(n=234)\end{array}$ & $\begin{array}{c}100 \% \\
(n=390)\end{array}$ \\
\hline
\end{tabular}

${ }^{*} \mathrm{p}<0,05$

Para comprobar la tercera hipótesis de investigación (H3) se consideraron únicamente las noticias firmadas por un hombre o mujer, esto es, se desestimaron las notas firmadas por un grupo mixto, staff, redacción, agencia o desconocidos, con el fin de comprobar si el sexo del reportero influyó en el tipo de encuadre desde el cual se evidenció a las primeras damas.

Los resultados disponibles en la tabla 5 indican que los varones tendieron a reportar mayor cantidad de noticias donde las mujeres fueron presentadas desde el encuadre menos politizado, este es, el de celebridad (35\%). Sin embargo, son los mismos varones los que las mostraron a partir del frame de funcionaria política (33\%) con apenas $1 \%$ más que las mujeres (32\%). Ellas, en cambio, mostraron mayor interés que los reporteros en el encuadre de directora de un proyecto (12\%), el cual también tiende a la politización.
Tabla 5. Encuadres noticiosos de acuerdo con el sexo del reportero que firmó la noticia

\begin{tabular}{|l|c|c|c|}
\hline Encuadre & Hombre & Mujer & \begin{tabular}{c} 
Total \\
\hline Funcionaria política
\end{tabular} \\
\hline Celebridad & 35 & 32 & $\begin{array}{c}33 \\
(\mathrm{n}=82)\end{array}$ \\
\hline Escolta presidencial & 13 & 20 & $\begin{array}{c}28 \\
(\mathrm{n}=71)\end{array}$ \\
\hline Anfitriona nacional & 7 & 15 & $\begin{array}{c}13 \\
(\mathrm{n}=35)\end{array}$ \\
\hline Directora de un proyecto & 5 & 14 & $\begin{array}{c}11 \\
(\mathrm{n}=26)\end{array}$ \\
\hline Altruista & 7 & $\begin{array}{c}8 \\
(\mathrm{n}=20)\end{array}$ \\
\hline Total & $\begin{array}{c}100 \% \\
(\mathrm{n}=138)\end{array}$ & $\begin{array}{c}100 \% \\
(\mathrm{n}=113)\end{array}$ & $\begin{array}{c}100 \% \\
(\mathrm{n}=251)\end{array}$ \\
\hline
\end{tabular}

$* p<0,05$ 
Debido a que la prueba estadística resultó no significativa, ya que $\chi^{2}(5, N=251)=10,91, p=0,053$, se rechazó la $\mathrm{H} 3$, con un coeficiente de contingencia bajo, $\mathrm{CC}=20 \%$. El presente estudio, por tanto, concluye que no existe una correspondencia significativa entre el sexo del reportero y el tipo de encuadre desde el cual se abordó a las primeras damas.
No existe una correspondencia significativa entre el sexo del reportero y el tipo de encuadre desde el cual se abordó a las primeras damas

La última pregunta de investigación indagó acerca de cuáles fueron los encuadres en los que las primeras damas participaron a través de citas directas, es decir, en qué medida y en cuáles marcos noticiosos se registró la voz de las cónyuges presidenciales. Para contestar dicha cuestión se formuló que:

\section{H4: Los diarios recurren a la voz de las primeras damas en encuadres politizados}

En términos generales, los diarios mostraron un bajo interés en mostrar la voz de estas mujeres en sólo el $36 \%$ de las noticias (ver tabla 6). Sin embargo, la mayoría de los mensajes periodísticos con citas directas se registró durante el encuadre de funcionaria política (41\%), seguido del relacionado con dirección de un proyecto (19\%). Por tanto, la voz de las mujeres se presentó en los roles menos tradicionales y más politizados del cargo protocolar.

Por otro lado, las declaraciones de las primeras damas fueron silenciadas en el encuadre de celebridad (37\%). De esta manera, cuando la esposa del mandatario fue cubierta como una famosa a través de sus características físicas y de imagen o de sus credenciales personales como ser hija o madre de alguien conocido, los diarios no tendieron a mostrar su voz, sino que solamente se habla sobre ella. Con lo anterior se puede concluir que los periódicos decidieron la agenda y los atributos que quieren mostrar sobre la figura política sin presentar la opinión de ésta.

Por tales motivos, es posible aceptar la $\mathrm{H} 4$ que indica que a mayor politización de los encuadres, mayor presencia de citas directas. La hipótesis se defiende a partir de la prueba $\chi^{2}(5, N=390)=$ 73,36, p=0,000, que indicó una asociación entre el uso de citas directas y los encuadres con un coeficiente de contingencia del $40 \%$.
Tabla 6. Participación de las primeras damas por medio de citas directas de acuerdo con los encuadres noticiosos

\begin{tabular}{|c|c|c|c|}
\hline Encuadre & $\begin{array}{l}\text { Sin citas } \\
\text { directas }\end{array}$ & $\begin{array}{l}\text { Con citas } \\
\text { directas }\end{array}$ & Total \\
\hline Funcionaria política & 25 & 41 & $\begin{array}{c}31 \\
(n=121)\end{array}$ \\
\hline Celebridad & 37 & 11 & $\begin{array}{c}27 \\
(n=107)\end{array}$ \\
\hline Escolta presidencial & 22 & 6 & $\begin{array}{c}16 \\
(n=62)\end{array}$ \\
\hline Anfitriona nacional & 8 & 15 & $\begin{array}{c}11 \\
(n=42)\end{array}$ \\
\hline Directora de un proyecto & 3 & 19 & $\begin{array}{c}9 \\
(n=34)\end{array}$ \\
\hline Altruista & 5 & 8 & $\begin{array}{c}6 \\
(n=24)\end{array}$ \\
\hline Total & $\begin{array}{c}100 \% \\
(n=251)\end{array}$ & $\begin{array}{c}100 \% \\
(n=139)\end{array}$ & $\begin{array}{c}100 \% \\
(n=390)\end{array}$ \\
\hline
\end{tabular}

${ }^{*} p<0,05$

\section{Conclusiones y discusión}

El hecho de que los periódicos mostraran a las cónyuges presidenciales como funcionarias políticas se presta a dos conclusiones. Primero, que los medios tendieron a ofrecer un paquete mediático en el que se expuso una pareja presidencial con ambiciones políticas (Watson, 1997). Lo anterior se desprende de que las primeras damas comparten responsabilidades con el presidente de manera que ellas ayudan a reducir la carga del trabajo de éste, difunden sus ideas políticas e incluso asisten a eventos en su representación (Kellerman, 1978; Gutin, 1989; Wekkin, 2000; Erickson; Thomson, 2012; Van-Wyk, 2017). De esta forma, en una parte de las noticias se cubrió como un mismo ente político a los binomios de los Clinton, los Bush, los Kirchner, los Macri, los Calderón-Zavala, etcétera, los cuales también comparten aceptación y popularidad (MacManus; Quecan, 2008; Marrs, 2018).

Una segunda inferencia que se refleja en una cobertura politizada es que los diarios les otorgaron el papel de estrategas político-electorales en tanto influyeron en campañas electorales y en el cabildeo de políticas públicas, lo que les otorga un capital político importante (Karlsdóttir, 2015; Shah, 2015; Gonnella-Platts; Fritz, 2017; Matějčková, 2019; Eweka, 2020).

Aunado a ello, de acuerdo con la relevancia que los diarios ofrecieron al encuadre político, las ubicaron desde un papel de poder. Si se adapta el concepto de soft power de Nye (2011), es posible concluir que los periódicos de la muestra apuntan a que si bien dicho puesto no las dota de un poder coercitivo como el que ostenta el presidente, las mujeres de este cargo poseen este poder blando que tiene cierta influencia en la opinión pública, por lo que la prensa suele buscar su opinión.

Es interesante observar que los dos encuadres más reiterados son opuestos entre sí, ya que la de funcionaria política (31\%) se refiere a las acciones que realiza en la arena pública y de manera activa, mientras que el de celebridad (27\%) se enfoca en las características de su esfera íntima y de forma pasiva como indicaron los estudios anteriores (Kalyango; Winfield, 2009; White; 2011; Zamora-Medina; Berná-Sicilia; Martínez-Martínez, 2014; Li, 2015; Matthews; Chaney; 
Opiri, 2015; Harmer, 2016; Widlak; Pont-Sorribes; Guillamet-Lloveras, 2016; Fernández-Fernández, 2017; Li; Yin, 2018; Rall et al., 2018; Gejdošová, 2019).

De este modo, los diarios suelen balancear ambas esferas para dar a entender que a pesar de ser figuras públicas aún conservan sus funciones en el espacio íntimo, y que a pesar de ser únicamente las esposas del mandatario, lo que hagan o piensen será motivo de escrutinio y de discusión política (Zheng, 2017). Este resultado es un buen indicio en tanto el retratar a las primeras damas desde distintas facetas que evidencien las diferentes y complejas identidades de las mujeres ayuda a romper el doble vínculo que existe entre la participación de las mujeres en política y su vida civil (Kitsch, 2017). En este sentido, cuando el encuadre de celebridad y funcionaria política se encuentran en un cierto equilibrio, los efectos de despolitización del frame de celebridad no parecen ser tan contundentes como lo señalaba Keohane (2017).

Sin embargo, la crítica hacia por qué justamente las mujeres deben ser abordadas desde ámbitos triviales sigue latente porque desvían la atención de temáticas centrales y no logran romper los estereotipos y expectativas sobre que las primeras damas representen cómo debe comportarse la mujer ideal de la nación (Aguilar-Castro, 2006; Stoltz, 2013; Kitsch, 2020). Esta conclusión es evidencia de los esfuerzos por atribuirles a estas figuras roles de género dentro de un entramado institucional

(Rojas-Zuluaga, 2018) y se enmarca en una conducta de los medios hacia infoentretener a las audiencias para obtener beneficios económicos (Sánchez-Zepeda; Echeverría-Victoria, 2018).

De las cuatro hipótesis planteadas, dos fueron rechazadas. La primera fue que no existe una asociación entre el sexo del reportero y el tipo de encuadres desde los que fueron abordadas las primeras damas, como lo habían precisado trabajos previos (Aday; Devitt, 2001; Cassidy, 2012; Vos, 2013; Conroy et al., 2015; Whalen, 2016). Si bien se registra un poco más de porcentaje en el frame político para los varones, Cassidy (2012) había explicado que esto ocurre porque los editores asignan más noticias políticas a hombres que a las mujeres, cuyas tareas tienen que ver con notas de corte humano.

El trabajo concluye también que existe una correlación entre la línea editorial del medio y el tipo de encuadres registrados, como lo señaló la bibliografía al respecto (Cassidy, 2012; Biachi, 2013; Wallström, 2017). La inferencia es que los medios opositores al gobierno en turno prefieren cubrir a las primeras damas a través del marco de funcionaria política, mientras que los similares ideológicamente al presidente se distinguen por mostrarlas como anfitrionas nacionales. Esto desestimó la hipótesis de que el comportamiento sería al revés. Si se toma en cuenta los resultados de estudios anteriores que indican que las primeras damas al ser abordadas desde encuadres políticos adquieren tonalidad negativa en el mensaje (Butler, 2013; Harmer, 2016) y una resistencia por parte de las audiencias (Vigil, 2014; Elder; Frederick, 2017), se podría entender por qué los diarios opositores tienen preferencia por este encuadre. Con ello es posible sostener la lógica de Matthes (2012) acerca de que los encuadres son construidos por opositores y defensores.

Entre las hipótesis comprobadas por el estudio se encuentra una mayor politización de las primeras damas con pasado político que las que no contaban con dicha experiencia. Así, las novatas fueron presentadas en mayor medida desde sus atributos como celebridades. También se registró, por medio del frame de escolta presidencial, que los diarios prefieren cubrir a las novatas junto con su esposo el presidente, mientras que a las expertas desde su individualidad. Por todo ello, este trabajo coincide con Eksterowicz y Roberts (2004) en que en el tipo de encuadre sobre una primera dama intervienen sus antecedentes personales.

Además, en el caso de las expertas, una mayor atención a sus atributos como funcionarias políticas pudo ampliar su trayectoria política debido a la naturaleza de dicho encuadre (Erickson; Thomson, 2012; Colton, 2016; Widlak; Pont-Sorribes; Guillamet-Lloveras, 2016; Van-Wyk, 2017; Matějčková, 2019), sobre todo en los casos de Fernández, Clinton y Zavala, quienes posteriormente buscaron la presidencia de su país, por lo que podría deberse a una estrategia electoral (Smith, 1997; MacManus; Quecan, 2008; Marrs, 2018).

En lo que corresponde a las primeras damas actuales, éstas fueron encuadradas en mayor medida que las ex cónyuges presidenciales como directoras de un proyecto, lo cual probó que los medios mantienen expectativas de que esta figura protocolar se haga de un proyecto (Shah, 2015). Las actuales también registraron mayor porcentaje en escolta presidencial (23\%) que sus predecesoras expertas (7\%), lo cual sustenta lo señalado por Burns (2004) de que las primeras damas recientes generan un retorno a la tradición como respuesta al precedente de una cónyuge presidencial con labores más politizadas. Ello también indica que los encuadres no se vuelven menos tradicionales con el paso del tiempo como apuntó Colton (2016). No obstante, debido a que el corpus incluyó la campaña electoral de su esposo, el encuadre político fue el más reiterado, por lo que habría que medir la evolución de su cargo con el paso del gobierno.

Por último se encontró que cuanto más politizados los encuadres, mayor oportunidad habrá de que las mujeres intervengan con sus opiniones a partir de citas directas (41\%). Pero también se halló que la participación de las primeras damas fue baja en declaraciones con apenas el 36\% de éstas, cosa que fue consistente con los antecedentes de investigación (Aday; Devitt, 2001; Llanos, 2014; Humprecht; Esser, 2017; Haraldsson; Wängnerud, 2019). En ese sentido, la 
cobertura por medio de frames como celebridad o escolta presidencial se centró más en lo que los reporteros hablaban sobre ellas y menos en lo que ellas tenían por decir, como habían reflexionado Kellerman (1978) y Gutin (1989), quienes vislumbraron un comportamiento pasivo de la figura política.

Así, esta investigación concluye en que los medios suelen abordar desde un encuadre político a las primeras damas lo cual será más recurrente si ellas tuvieron un pasado político y si el medio es ideológicamente opuesto al gobierno en cuestión y no tanto en consonancia con el tiempo, como lo sustentó el estudio de las actuales cónyuges presidenciales.

Una limitante del estudio fue que no se compararon los resultados entre países con sistemas políticos y mediáticos diferentes. En ese sentido, se sugiere como línea de investigación un análisis que evidencie la participación de estas variables en la conformación de encuadres. Asimismo, se invita a utilizar este modelo de frames en otros contextos para conocer el grado de politización o despolitización de esta figura política.

\section{Referencias}

Aday, Sean; Devitt, James (2001). "Style over substance: newspaper coverage of Elizabeth Dole's presidential bid". The international journal of press/politics, v. 6, n. 2, pp. 52-73.

https://doi.org/10.1177/108118001129172134

Aguilar-Castro, Alicia (2006). Primeras damas, las ausentes presentes. Ciudad de México: Documentación y Estudios de Mujeres, A. C. ISBN: 9686851607

Álvarez-Monsiváis, Edrei (2019). “Encuadres noticiosos en la cobertura de primeras damas: aportes teóricos y metodológicos". Razón y palabra, v. 23, n. 105, pp. 242-281.

http://www.revistarazonypalabra.org/index.php/ryp/article/view/1577

Amato, Alberto (2019). "Primeras damas: la historia argentina vista de cerca". Clarín, 16 diciembre. https://bit.ly/3jP8ylk

Ardèvol-Abreu, Alberto (2015). “Framing o teoría del encuadre en comunicación. Orígenes, desarrollo y panorama actual en España". Revista latina de comunicación social, n. 70, pp. 423-450.

https://doi.org/10.4185/RLCS-2015-1053

Ares, Carlos (1990). “La esposa y los hijos de Menem dejan la residencia presidencial argentina”. El país, 12 junio. https://bit.ly/3fd66Yh

Aruguete, Natalia (2017). “Agenda setting y framing: un debate teórico inconcluso”. Más poder local, n. 30, pp. 36-42. https://bit.ly/2WNeMyd

Barry, Carolina (2018). "Se hace la Evita... primeras damas y política provincial". Revista de historia americana y argentina, v. 53, n. 2, pp. 143-160.

https://bdigital.uncu.edu.ar/11326

Beasley, Maurine H. (2005). First ladies and the press. The unfinished partnership of the media age. Evanston: Northwestern University Press. ISBN: 9780810123120

Benavides, José-Luis; Quintero, Carlos (2005). Escribir en prensa. Madrid: Pearson. ISBN: 9788420542294

Biachi, Mariangela-Monfardini (2013). O feminino nas eleições de 2010: o discurso de Veja e Istoé sobre as mulheres candidatas. Tesis de maestría. Universidade de Brasília.

https://repositorio.unb.br/handle/10482/13438

Bleich, Erik; Stonebraker, Hannah; Nisar, Hasher; Abdelhamid, Rana (2015). “Media portrayals of minorities: Muslims in British newspaper headlines, 2001-2012". Journal of ethnic and migration studies, v. 41, n. 6, pp. 942-962.

https://doi.org/10.1080/1369183X.2014.1002200

Borrelli, MaryAnne (2002). "Telling it slant: gender roles, power, and narrative style in the first ladies' autobiographies". Sex roles, v. 47, n. 7-8, pp. 355-370.

https://link.springer.com/content/pdf/10.1023/A:1021483131794.pdf

Borrelli, MaryAnne; Tenpas, Kathryn-Dunn; Wright, Lauren A. (2017). The office of the first lady. Washington: The White House Transition Project.

https://bit.ly/3jQJh08

Brussino, Silvina; García, Ana-Pamela-Paz; Rabbia, Hugo H.; Imhoff, Débora (2011). "Ideología política y prácticas mediatizadas de consumo informativo". Revista debates, v. 5, n. 2, pp. 13-40.

https://doi.org/10.22456/1982-5269.22678

Burns, Lisa M. (2004). First ladies as political women: press framing of presidential wives, 1900-2001. PhD thesis. University of Maryland.

http://hdl.handle.net/1903/1968 
Bush, Laura (2002). Ready to read, ready to learn. An education initiative by Laura Bush. https://www.govinfo.gov/app/details/ERIC-ED469448

Butler, Jazmyne E. (2013). Professional first ladies in the media: Framing of Clinton, Bush, and Obama in The Washington Post. Bachelor's thesis. The University of Southern Mississippi.

https://aquila.usm.edu/honors_theses/148

Cassidy, Kathryn M. (2012). Bringing the frame into focus: how cable news pundits protect the glass ceiling. Master thesis. University of Massachusetts.

https://scholarworks.umass.edu/theses/841

Catalán-Matamoros, Daniel; Peñafiel-Saiz, Carmen (2019). “Medios y desconfianza en vacunas: un análisis de contenido en titulares de prensa". Revista latina de comunicación social, n. 74, pp. 786-802.

https://doi.org/10.4185/RLCS-2019-1357

Cision Media Research (2019). Top 10 U.S. daily newspapers.

https://cisn.co/3gkQROw

Colton, Jennifer (2016). The first lady of the United States: a traditional role in the modern era. Bachelor's thesis. Duke University. https://bit.ly/2yASQOm

Conroy, Meredith; Oliver, Sarah; Breckenridge-Jackson, Ian; Heldman, Caroline (2015). "From Ferraro to Palin: sexism in coverage of vice presidential candidates in old and new media". Politics, groups, and identities, v. 3, n. 4, pp. 573-591. https://doi.org/10.1080/21565503.2015.1050412

Corrigan, Matthew (2000). "The transformation of going public: president Clinton, the first lady, and health care reform". Political communication, v. 17, n. 2, pp. 149-168.

https://doi.org/10.1080/105846000198459

De-Vreese, Claes H. (2005). “News framing: theory and typology”. Information design journal, v. 13, n. 1, pp. 51-62. https://doi.org/10.1075/idjdd.13.1.06vre

Durán-Gracia, Miguel-Agustín (2009). La ideología en los medios: una propuesta para un mapa conceptual de la prensa en México. Tesis de maestría. Instituto Tecnológico y de Estudios Superiores de Monterrey.

http://hdl.handle.net/11285/572959

Eksterowicz, Anthony J.; Roberts, Robert N. (2008). "First ladies: constitutional and job description problems?". Politics \& policy, v. 32, n. 3, pp. 412-433.

https://doi.org/10.1111/j.1747-1346.2004.tb00190.x

Elder, Laurel; Frederick, Brian (2019). "Perceptions of candidate spouses in the 2012 presidential election: the role of gender, race, religion, and partisanship". Politics, groups, and identities, v. 7, n. 1, pp. 109-130.

https://doi.org/10.1080/21565503.2017.1338969

Entman, Robert M. (1993). "Framing: toward clarification of a fractured paradigm". Journal of communication, v. 43, n. 4, pp. 51-58.

https://doi.org/10.1111/j.1460-2466.1993.tb01304.x

Erickson, Keith V.; Thomson, Stephanie (2012). "First lady international diplomacy: performing gendered roles on the world stage". Southern communication journal, v. 77, n. 3, pp. 239-262.

https://doi.org/10.1080/1041794X.2011.647502

Eweka, Osagioduwa (2020). "Working behind the scenes: rethinking peace and development in the first lady illusory continuum of afropolicom". In: Omotoso, Sharon-Adetutu. Women's political communication in Africa, pp. 133-154. Cham: Springer. ISBN: 9783030428266

Fernández-Fernández, Lorena (2017). La figura de la primera dama (Flotus) en las revistas estadounidenses: Michelle Obama y Melania Trump. Universidad de Valladolid: Segovia.

http://uvadoc.uva.es/handle/10324/24806

Finneman, Teri; Thomas, Ryan J. (2014). “First ladies in permanent conjuncture: Grace Coolidge and 'great' American womanhood in The New York Times". Women's studies in communication, v. 37, n. 2, pp. 220-236.

https://doi.org/10.1080/07491409.2014.911232

Gejdošová, Iva (2019). Social media and gender in political campaigns: the role of candidate's spouses in the Czech Republic. Bachelor's thesis. Charles University.

https://bit.ly/2WX1ejO

Goffman, Erving (1979). Gender advertisements. New York: Harper Press. ISBN: 9780060906337 
Gonnella-Platts, Natalie; Fritz, Katherine (2017). Un papel sin guión: influencia y liderazgo de las primeras damas a nivel mundial. Dallas: George W. Bush Institute.

https://gwbcenter.imgix.net/Resources/fli-report/GWBI-Role-Without-a-Rulebook-spanish.pdf

Guerrero-Valencia, Carolina (2015). “Una mirada al rol de la primera dama en América Latina”. Hispanorama, n. 150, pp. 54-59.

https://bit.ly/2SDDtve

Guerrero-Valencia, Carolina; Arana-Araya, Ignacio (2019). "Las primeras damas como miembros de la élite política". América Latina hoy, n. 81, pp. 31-49.

https://doi.org/10.14201/alh201981

Gutin, Myra G. (1989). The president's partner: the first lady in the Twentieth Century. New York: Praeger. ISBN: 9780 313253355

Haraldsson, Amanda; Wängnerud, Lena (2019). "The effect of media sexism on women's political ambition: evidence from a worldwide study". Feminist media studies, v. 19, n. 4, pp. 525-541.

https://doi.org/10.1080/14680777.2018.1468797

Harmer, Emily (2016). “Public to private and back again: the role of politicians' wives in British election campaign coverage". Feminist media studies, v. 16, n. 5, pp. 852-868.

https://doi.org/10.1080/14680777.2015.1105841

Higgins, Michael; Smith, Angela (2013). “'My husband; my hero': selling the political spouses in the 2010 general election". Journal of political marketing, v. 12, n. 2-3, pp. 197-210.

https://doi.org/10.1080/15377857.2013.781473

Ho, Daniel E.; Quinn, Kevin M. (2008). “Measuring explicit political positions of media”. Quarterly journal of political science, v. 3, n. 4, pp. 353-377.

https://doi.org/10.1561/100.00008048

Humprecht, Edda; Esser, Frank (2017). "A glass ceiling in the online age? Explaining the underrepresentation of women in online political news". European journal of communication, v. 32, n. 5, pp. 439-456.

https://doi.org/10.1177/0267323117720343

Igartua, Juan-José (2012). "Tendencias actuales en los estudios cuantitativos en comunicación”. Comunicación y sociedad, n. 17, pp. 15-40.

http://www.comunicacionysociedad.cucsh.udg.mx/index.php/comsoc/article/view/273

Igartua, Juan-José; Humanes, María-Luisa (2004). Teoría e investigación en comunicación social. Madrid: Síntesis. ISBN: 9788497562263

Igartua, Juan-José; Muñiz, Carlos; Cheng, Lifen (2005). “La inmigración en la prensa española: aportaciones empíricas y metodológicas desde la teoría del encuadre noticioso". Migraciones, n. 17, pp. 143-181.

https://revistas.comillas.edu/index.php/revistamigraciones/article/view/4220

Infobae (2020). “El papel de la esposa del presidente: quiénes fueron las últimas primeras damas de México". Infobae, 7 julio. https://bit.ly/2BEu1/P

Instituto Nacional Electoral (2019). Catálogo nacional de medios impresos e internet 2019.

https://bit.ly/37EjzVn

Instituto Verificador de Circulaciones (2019). El boletín express 2019.

https://bit.ly/3bu8geX

Jackson, Christopher K. (2012). "Let's move": examining first lady Michelle Obama's childhood obesity campaign in the news media. PhD thesis. Howard University.

https://bit.ly/3jKI8Yd

Kalyango, Yusuf; Winfield, Betty H. (2009). "Rhetorical media framing of two first lady political candidates across cultures". Global media journal, v. 8, n. 15, art. 7.

https://bit.ly/2Wa9sFI

Karlsdóttir, Kristín-Sandra (2015). The national grandmother, the co-president and the "mom-in-chief": defining the role and characteristics of the "typical" first lady. Bachelor's thesis. Háskóli Íslands.

http://hdl.handle.net/1946/20950

Kellerman, Barbara (1978). "The political functions of the presidential family". Presidential studies quarterly, v. 8, n. 3, pp. 303-318.

https://www.jstor.org/stable/27547410 
Keohane, Jennifer (2017). "The most important dress in the country: the rhetoric of glamour in the Smithsonian's 'The first ladies'”. Women's studies in communication, v. 40, n. 3, pp. 270-288.

https://doi.org/10.1080/07491409.2017.1346531

Kitsch, Sara-Rae (2017). "Minting public memory: substitution logics and gendered commemoration in the first spouse coin". Women's studies in communication, v. 40, n. 4, pp. 419-439.

https://doi.org/10.1080/07491409.2017.1373717

Kitsch, Sara-Rae (2020). "The contained citizen: first ladies, public memory, and the rhetoric of visual containment". Communication quarterly, v. 68, n. 2, pp. 138-160.

https://doi.org/10.1080/01463373.2019.1709089

Krippendorff, Klaus (1990). Metodología de análisis de contenido: teoría y práctica. Buenos Aires: Paidós Comunicación. ISBN: 8475096271

Krippendorff, Klaus (2017). "Reliability". In: Matthes, Jörg. The international encyclopedia of communication research methods. New Jersey: John Wiley \& Sons. ISBN: 9781118901762

Lawson, Chappell H. (2002). Building the fourth Estate. Democratization and the rise of a free press in Mexico. Berkeley: University of California Press. ISBN: 9780520231719

Li, Shuo (2015). A cross-national comparison of news coverage of Michelle Obama's visit to China in American and Chinese media. Master thesis. Iowa State University.

https://doi.org/10.31274/etd-180810-4091

Li, Zongya; Yin, Yiyi (2018). "Attractiveness, expertise and closeness: the effect of source credibility of the first lady as political endorser on social media in China". Global media and China, v. 3, n. 4, pp. 297-315.

https://doi.org/10.1177/2059436418819228

Lizárraga, Daniel; Cabrera, Rafael; Huerta, Irving; Barragán, Sebastián (2015). La casa blanca de Peña Nieto: la historia que cimbró un gobierno. Ciudad de México: Grijalbo. ISBN: 9786073136426

Llanos, Beatriz (2014). Ojos que (aún) no ven. Nuevo reporte de ocho países: Género, campañas electorales y medios en América Latina. Lima: IDEA, ONU. ISBN: 9789186565671

Lozano, José-Carlos (1994). "Hacia la reconsideración del análisis de contenido en la investigación de los mensajes comunicacionales". En: Cervantes-Barba, Cecilia; Sánchez-Ruiz, Enrique E. Investigar la comunicación. Propuestas iberoamericanas, pp. 135-157. Guadalajara: Universidad de Guadalajara, Centro de Estudios de la Información y la Comunicación. ISBN: 9688955779

Mackey-Kallis, Susan; Hahn, Dan F. (1991). "Questions of public will and private action: the power of the negative in the Reagans' "just say no" morality campaign”. Communication quarterly, v. 39, n. 1.

https://doi.org/10.1080/01463379109369779

MacManus, Susan A.; Quecan, Andrew F. (2008). "Spouses as campaign surrogates: strategic appearances by presidential and vice presidential candidates' wives in the 2004 election". PS: Political science \& politics, v. 41, n. 2, pp. 337-348. https://doi.org/10.1017/S1049096508080529

Marrs, Brittany L. (2018). The woman behind the eagle: impact of the character of the first lady on presidential approval ratings. Master thesis. Sam Houston State University.

http://hdl.handle.net/20.500.11875/2391

Matějčková, Anna (2019). What type of first lady was Michelle Obama: case study on Michelle Obama as first lady. Master thesis. Charles University. https://is.cuni.cz/webapps/zzp/detail/193280/?lang=en

Matthes, Jörg (2012). "Framing politics: an integrative approach". American behavioral scientist, v. 56, n. 3, pp. $247-259$. https://doi.org/10.1177/0002764211426324

Matthews, Delisia; Chaney, Cassandra; Opiri, Jane A. (2015). "The Michelle Obama influence: an exploration of the first lady's fashion, style, and impact on women". Fashion and textiles, v. 2, n. 1.

https://doi.org/10.1186/s40691-015-0050-9

Mayo, Edith P. (2000). "Party politics: the political impact of the first ladies' social role". The social science journal, v. 37, n. 4, pp. 577-590.

https://doi.org/10.1016/S0362-3319(00)00097-5

McBride, Anita (2016). "Laura Welch Bush: strength and serenity in turbulent times". In: Sibley, Katherine A.S. A companion to first ladies, pp. 653-676. Chichester: Wiley-Blackwell. ISBN: 9781118732229 
McCombs, Maxwell; Ghanem, Salma I. (2001). "The convergence of agenda setting and framing”. In: Reese, Stephen D.; Gandy Jr., Oscar H.; Grant, August E. Framing public life. Perspectives on media and our understanding of the social world, pp. 67-82. Mahwah: Lawrence Erlbaum Associates. ISBN: 9780805849264

Molteni, Camila (2016). "Gracias por existir". Medium, 28 junio.

https://bit.ly/2X4OyYo

Mortensen, Tara (2015). "Visually assessing the first lady in a digital age: study of Michelle Obama as portrayed by journalists and the white house". Journal of women, politics \& policy, v. 36, n. 1, pp. 43-67.

https://doi.org/10.1080/1554477X.2015.985152

Nye, Joseph S. (2011). The future of power. New York: Politic Affairs. ISBN: 9781610390699

O’Connor, Karen; Nye, Bernadette; Van-Assendelft, Laura (1996). "Wives in the white house: the political influence of first ladies". Presidential studies quarterly, v. 26, n. 3, pp. 835-853.

https://www.jstor.org/stable/27551636

Paul, Newly; Perreault, Gregory (2018). “The first lady of social media: the visual rhetoric of Michelle Obama's Twitter images". Atlantic journal of communication, v. 26, n. 3, pp. 164-179.

https://doi.org/10.1080/15456870.2018.1472092

Piñeiro-Naval, Valeriano; Mangana, Rafael (2018). “Teoría del encuadre: panorámica conceptual y estado del arte en el contexto hispano". Estudios sobre el mensaje periodístico, v. 24, n. 2, pp. 1541-1557.

https://doi.org/10.5209/ESMP.62233

Rall; Denise N.; Coghlan, Jo; Hackett, Lisa J.; Boyd, Anitta (2018). “Dressing up two democratic first ladies: fashion as political performance in America. Australasian journal of popular culture, v. 7, n. 2, pp. 273-287.

https://doi.org/10.1386/ajpc.7.2.273_1

Rodelo, Frida V.; Muñiz, Carlos (2017). "La orientación política del periódico y su influencia en la presencia de encuadres y asuntos dentro de las noticias". Estudios sobre el mensaje periodístico, v. 23, n. 1, pp. 241-256.

https://doi.org/10.5209/ESMP.55594

Rojas-Zuluaga, Mariana (2018). Papel de la primera dama en Colombia: análisis de su rol simbólico. Tesis de licenciatura. Pontificia Universidad Javeriana.

https://repository.javeriana.edu.co/handle/10554/48264

Sánchez-Zepeda, Galia; Echeverría-Victoria, Martín (2018). “Infoentretenimiento y clientelismo en la cobertura periodística de la violencia política de género. Entre la conveniencia y la ignorancia”. En: Navarro-Sequeira, Melva-Guadalupe. El proceso electoral de México 2018 ¿Y las candidatas?, pp. 23-34. Puebla: Montiel \& Soriano. ISBN: 9786077512844

Shah, Siddra (2015). First ladies in the press: analysis of New York times coverage of Hillary Clinton, Laura Bush, and Michelle Obama. Honour thesis. Syracuse University.

https://surface.syr.edu/honors_capstone/855

Shoop, Tiffany J. (2010). "From professionals to potential first ladies: how newspapers told the stories of Cindy McCain and Michelle Obama”. Sex roles, v. 63, n. 11, pp. 807-819.

https://doi.org/10.1007/s11199-010-9858-3

Smith, Kathy B. (1997). "The first lady represents America: Rosalynn Carter in South America". Presidential studies quarterly, v. 27, n. 3, pp. 540-548.

https://www.jstor.org/stable/27551767

Smith, Nancy-Kegan; Carlin, Diana B. (2016). "First lady Michelle Obama: the American dream endures". In: Sibley, Katherine A. S. A companion to first ladies, pp. 677-695. Hoboken: Wiley-Blackwell. ISBN: 9781118732229

Soengas-Pérez, Xosé (2007). “El control de la información en televisión”. Ámbitos, v. 18, n. 16, pp. 325-341.

https://doi.org/10.12795/ambitos.2007.i16.18

Stoltz, Elizabeth-Anne (2013). "Beyond the pillow talk: how gender, media and politics shape the role and legacy of first ladies, 1961-2012". In: The national conference on undergraduate research (NCUR).

https://www.ncurproceedings.org/ojs/index.php/NCUR2013/article/view/472

Sullivan, Amy (2018). First impressions: an analysis of media coverage of first ladies and their inaugural gowns form Jackie Kennedy in 1961 to Michelle Obama in 2009. Master thesis. University of Alabama.

http://ir.ua.edu/handle/123456789/5169

Taglianetti, Julia (2019). "Press attention and public admiration: the historical significance of celebrity first ladies". Hayes history journal, n. 3, pp. 55-72.

https://bit.ly/2OXLQzy 
Tiscareño-García, Elizabeth; Miranda-Villanueva, Oscar-Mario (2020). "Víctimas y victimarios de feminicidio en el lenguage de la prensa escrita mexicana". Comunicar, v. 28, n. 63, pp. 51-60. https://doi.org/10.3916/C63-2020-05

Valenzuela, Sebastián; Correa, Teresa (2006). “Prensa y candidatos presidenciales 2005. Así los mostramos, así los miraron". Cuadernos.info, n. 19, pp. 89-96.

https://doi.org/10.7764/cdi.19.129

Valera-Ordaz, Lidia (2016). “El sesgo mediocéntrico del framing en España: una revisión crítica de la aplicación de la teoría del encuadre en los estudios de comunicación”. Zer, v. 21, n. 41, pp. 13-31.

https://doi.org/10.1387/zer.16404

Van-Wyk, Jo-Ansie (2017). “The first ladies of Southern Africa: trophies or trailblazers?”. Politikon, v. 44, n. 1, pp. 157172.

https://doi.org/10.1080/02589346.2017.1279804

VanHorn, Abigaile-Marguerite (2010). Candidate wives: spouses as strategic surrogates on the presidential campaign trail. PhD thesis. Purdue University.

https://docs.lib.purdue.edu/dissertations/AAI3453394

Vargas, Monserrat (2018). "Cuál era el papel histórico de las primeras damas de México y cuál es ahora". Publimetro, 20 noviembre.

https://bit.ly/3faDfUw

Vigil, Tammy R. (2014). “Feminine views in the feminine style: convention speeches by presidential nominees' spouses”. Southern communication journal, v. 79, n. 4, pp. 327-346.

https://doi.org/ 10.1080/1041794X.2014.916339

Villamil, Jenaro (2004). “En duda, la transparencia de la fundación encabezada por Sahagún”. La jornada, 3 febrero. https://bit.ly/3hO9pXY

Vos, Debby (2013). "The vertical glass ceiling: explaining female politicians' underrepresentation in television news". Communications, v. 38, n. 4, pp. 389-410.

https://doi.org/10.1515/commun-2013-0023

Wachai, James-Njoroge (2005). Journalistic gender stereotyping of first ladies Laura Bush and Hillary Clinton. PhD thesis. Egerton University. https://bit.ly/2WD1ljy

Wagner, María-Celeste (2019). "Género de periodistas e influencia: efectos sobre la gravedad percibida del acoso sexual". Cuadernos.info, n. 44, pp. 43-59.

https://doi.org/10.7764/cdi.44.1631

Wallström, Sven (2017). A critical discourse analysis of the media portrayal of Melania Trump as first lady. Umeå University: Umeå, Sweden.

https://bit.ly/3b7SOKJ

Watson, Robert P. (1997). "The first lady reconsidered: presidential partner and political institution”. Presidential studies quarterly, v. 27, n. 4, pp. 805-818.

https://www.jstor.org/stable/27551802

Weaver, David A.; Lively, Erica; Bimber, Bruce (2009). "Searching for a frame: news media tell the story of technological progress, risk, and regulation". Science communication, v. 31, n. 2, pp. 139-166.

https://doi.org/10.1177/1075547009340345

Wekkin, Gary D. (2000). "Role constraints and first ladies". The social science journal, v. 37, n. 4, pp. 601-610. https://doi.org/10.1016/S0362-3319(00)00099-9

Whalen, Sheri (2016). “Coverage of the 2008 presidential primary campaign by male, females, and mixed journalist groups". Speaker \& gavel, v. 53, n. 1, pp. 103-129.

https://bit.ly/2uSmFbc

White, Khadijah L. (2011). "Michelle Obama: redefining the (white) house-wife". Thirdspace, v. 10, n. 1.

http://journals.sfu.ca/thirdspace/index.php/journal/article/view/white

Wideman, Stephanie L. (2017). Pathetic politics: an analysis of emotion and embodiment in first lady rhetoric. PhD thesis. Wayne State University.

https://digitalcommons.wayne.edu/cgi/viewcontent.cgi?article=2752\&context=oa_dissertations 
Widlak, Ewa (2017). The first lady: from the kitchen to the podium. How the gender equality revolution and the media forged a new political actor in democratic systems. Tesis doctoral. Universitat Pompeu Fabra.

http://hdl.handle.net/10803/40243

Widlak, Ewa; Pont-Sorribes, Carles; Guillamet-Lloveras, Jaume (2016). “Behold... the head of State's spouse! A comparative study of the political rise of the first lady in Poland, France and Spain". Anàlisi: quaderns de comunicació i cultura, n. 55 , pp. 68-84.

https://doi.org/10.7238/a.v0i55.2939

Winfield, Betty-Houchin (1997). "The first lady, political power and the media: who elected her anyway?". In: Norris, Pipa. Women, media, and politics. New York: Oxford University Press. ISBN: 9780195105674

Winfield, Betty-Houchin; Friedman, Barbara (2003). “Gender politics: news coverage of the candidates' wives in campaign 2000". Journalism \& mass communication quarterly, v. 80, n. 3, pp. 548-566.

https://doi.org/10.1177/107769900308000305

Zamora-Medina, Rocío; Berná-Sicilia, Celia; Martínez-Martínez, Helena (2014). "La retórica emocional de la esposa del candidato: análisis lingüístico de los discursos de Michelle Obama y Ann Romney". Estudios sobre el mensaje periodístico, v. 20, n. 1, pp. 585-612.

https://doi.org/10.5209/rev_ESMP.2014.v20.n1.45250

Zeldes, Geri-Alumit (2009). “Maverick, escort, or style setter - TV news framing of candidates' spouses during the 2004 and 2008 presidential elections. Electronic news, v. 3, n. 4, pp. 193-213.

https://doi.org/10.1080/19312430903300012

Zepeda, Mayra (2012). "Fundadora de la Guardería ABC fue absuelta por la muerte de 49 niños, denuncian padres". Animal político, 12 enero.

https://bit.ly/3jP4UOZ

Zhang, Lei (2017). "The soft power of a first lady - constructing identities for first ladies in the Chinese and American media". Discourse, context \& media, v. 20, pp. 33-44.

https://doi.org/10.1016/j.dcm.2017.07.005

Zorthian, Julia (2016). "Read Melania Trump's campaign speech addressing cyberbullying". Time, 3 Nov. https://time.com/4557033/transcript-melania-trump-campaign-speech

\section{Da visibilidad a tu trabajo depositándolo en e-LIS, el mayor repositorio internacional sobre biblioteconomía, documentación y comunicación}

\section{$e$ - LiS}
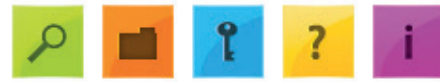

Login | Create Account

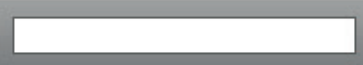

Welcome to e-Lis Repository

Latest additions

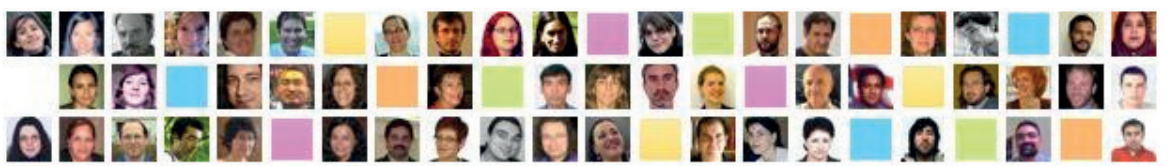

Search

the repository using a full range of fields

http://eprints.rclis.org 